\title{
Dissociação entre forma e estrutura harmônica em obras de Claude Debussy e Igor Stravinsky
}

\section{Dissociation Between Harmonic Form and Structure in works by Claude Debussy and Igor Stravinsky}

\author{
iD Adriano Claro Monteiro ${ }^{1}$ \\ Universidade Federal de Goiás, Goiânia, Goiás, Brasil \\ adrianomonteiro@ufg,br
}

\begin{abstract}
Resumo: Neste artigo apresentamos análises do Prelúdio X, Livro II, intitulado Canope, de Claude Debussy e da Introdução à primeira parte do balé A Sagração da Primavera de Igor Stravinsky. Nosso trabalho enfoca o conteúdo harmônico destas peças que são interpretadas através de métodos tradicionais de análise harmônica tonal, como o detalhado por Walter Piston em seu livro Harmony, bem como sob a luz de técnicas de organização de alturas comuns aos compositores das vertentes estéticas estudadas, como as compiladas por Stefan Kostka e Matthew Santa. Nossos resultados mostram como essas obras, provenientes da produção de compositores de estéticas e gerações distintas, compartilham uma mesma caraterística: a dissociação entre a forma e a estrutura harmônica. Em ambos os casos, embora como resultantes de procedimentos distintos de organização harmônica, encontramos um plano organizacional subjacente inspirado no sistema tonal que subsidia a criação de uma harmonia sem traços perceptíveis de relações tonais.
\end{abstract}

Palavras-chave: Claude Debussy. Igor Stravinsky. Análise Harmônica. Prelúdio X. Canope. A Sagração da Primavera.

\footnotetext{
1 Professor Adjunto em Composição e linguagem musical na Escola de Música e Artes Cênicas (EMAC) da Universidade Federal de Goiás (UFG). Doutor em Música pela Universidade Estadual de Campinas (UNICAMP). Seus interesses abrangem as áreas de composição musical, música eletroacústica e computacional, análise musical do repertório do século XX e XXI, desenvolvimento sistemas musicais interativos, instalações multimídia, recuperação de informação musical e musicologia sistemática.
} 


\begin{abstract}
In this paper we present analyses of the Prelude X, Book II, entitled Canope, by Claude Debussy, and of the Introduction to the first part from the ballet The Rite of Spring by Igor Stravinsky. Our work focuses on the harmonic content of these pieces which are interpreted through traditional methods for analysis of tonal harmony, such as the detailed by Walter Piston is his book "Harmony", as well in the light of techniques for pitch organization common to composers of the aesthetics studied here, as the ones compiled by Stefan Kostka e Matthew Santa. Our results show how these works, output of composers from different aesthetics and generations, share a same characteristic: the dissociation between harmonic form and structure. In both cases, even though as results of different procedures for harmonic organization, we found a background organizational layer inspired by the tonal system that supports the creation of a harmony without perceptible traces of tonal relations.
\end{abstract}

Keywords: Claude Debussy. Igor Stravinsky. Harmonic Analysis. Prelude X. Canope. The Rite of Spring.

Submetido em: 2 de junho de 2020.

Aceito em: 19 de novembro de 2020. 
Dissociação entre forma e estrutura harmônica em obras de Claude Debussy e Igor... Adriano Claro Monteiro

\section{Introdução}

Canope (DEBUSSY, 1913, p. 55-57) e A Sagração da Primavera (Le Sacre du Printemps) (STRAVINSKY, 2000) são obras que tiveram sua estreia e primeira publicação no ano de $1913^{2}$ (HOFFMAN, 2002; NEFF, CARR e HORLACHER, 2017). Diametralmente diferentes em porte - a primeira, um singelo prelúdio para piano com duração aproximada de três minutos, a segunda, uma forte suíte de balé para grande orquestra e duração aproximada de trinta e três minutos - foram compostas por dois dos maiores nomes da música de concerto do século XX, respectivamente, Claude Debussy e Igor Stravinsky.

Uma geração separa esses dois músicos. Em 1913 Debussy estava com 51 anos de idade enquanto Stravinsky tinha 31. A música do compositor francês é para muitos um marco histórico da passagem do romantismo para o modernismo musical (GRIFFTHS, 1998), ainda que seja usualmente classificada sob o termo 'impressionista'. Desde 1909 Stravinsky vivia em Paris a convite do empresário Sergey Diaghilev, para criação de balés comissionados para a companhia Balés Russos. Esse período marca a primeira fase composicional de Stravinsky com a produção de obras inspiradas no folclore de sua terra natal.

No ano de 1913, ambos, Debussy e Stravinsky, estrearam balés junto à companhia de Diaghlev. A obra Jeux de Debussy estreou duas semanas antes de A Sagração da Primavera, mas foi ofuscada pela polêmica gerada em torno do balé do compositor russo (FAUSER, 2017). No mesmo ano, Debussy publica o segundo livro de prelúdios para piano e sua estreia ocorre em Londres ainda em 1913. Canope é a décima peça do livro e o título faz referências aos vasos canópicos (HOFFMAN, 2002): urnas utilizadas no Egito Antigo para armazenar os órgãos vitais de pessoas mumificadas que, segundo a crença, eram essenciais para garantir-Ihes a

2 Sobre informações biográficas de Debussy ver: Centre de Documentation Claude Debussy, Biographie - 1910-1914. Disponível em: http://www.debussy.fr/cdfr/bio/bio6_10-14.php. Acesso em: 30 mai. 2020. A primeira partitura de A Sagração da Primavera, publicada por Stravinsky em 1913, foi uma redução para piano a duas mãos. 
Dissociação entre forma e estrutura harmônica em obras de Claude Debussy e Igor... Adriano Claro Monteiro

vida após a morte. Aparentemente simples e com pequeno porte, Canope é uma obra frequentemente utilizada para fins didáticos, por exemplo, o livro sobre teoria musical de Ralph Turek (1996, p. 309-311) a cita integralmente em um exercício de análise no capítulo dedicado à música tonal do início do século XX, assim como a utiliza William (1997, p. 156-158), e também Kostka e Santa (2018, p. 47), que citam os cinco compassos finais da peça para exemplificar acordes com dissonâncias adicionadas. Hofmann (2002) dedica um artigo completo à análise de Canope no qual propõe uma interpretação narrativa à peça inspirada em seu título e associada ao seu desdobramento formal. O autor também sugere correspondências entre a introdução do prelúdio e alguns dos elementos de estruturação das demais partes da música.

A suíte de balé $A$ Sagração da Primavera dispensa apresentações. É o terceiro da série de balés com temáticas folclóricas russas compostos para a companhia Balés Russos de Sergey Diaghilev. Causou polêmica em sua estreia e alguns anos depois obteve grande reconhecimento. Ainda hoje, mais de um século depois, é umas das obras mais tocadas por orquestras ao redor do mundo no que concerne ao repertório da música do século XX. É um marco da estética do primeiro modernismo musical e uma importante influência para as gerações seguintes.

Interpretações analíticas dessa obra têm figurado entre os escritos teóricos de nomes proeminentes da música do século $\mathrm{XX}$, como Pierre Boulez (1968, p. 72-145) e Olivier Messiaen (1995, p. 93-150). Ainda que a análise de Messiaen tenha sido anterior, feita como conteúdo das aulas do compositor no Conservatório de Paris, na primeira metade do século XX, elas vieram ao conhecimento do grande público apenas em 1995 com a publicação póstuma do segundo volume do Traité de rythme, de couleur, et d'ornithologie, diferentemente do que ocorreu com a análise realizada por Pierre Boulez em seu bem conhecido texto Stravinsky Permanece, de 1953, que decerto moldou muito da percepção sobre a obra desde então (CHEONG, 2019, p. 15-16). Ambos os autores concordam que a principal contribuição trazida por Stravinsky 
Dissociação entre forma e estrutura harmônica em obras de Claude Debussy e Igor... Adriano Claro Monteiro

à música ocidental com $A$ Sagração... concerne à inovação rítmica e emancipação do ritmo como parâmetro de primeira importância na organização musical. Messiaen, por exemplo, argumenta que a sequência de acordes repetidos e aperiodicamente acentuados do início Les Augures printaniers é o primeiro tema puramente rítmico da histórica da música ocidental (Messaien, 1995, p. 99).

Ao longo dos anos, outros autores contribuíram com textos analíticos e contextualizações históricas sobre $A$ Sagração... Dentre eles, uma parcela significativa enfoca os aspectos rítmicos, como as análises realizadas por Code (2007), os capítulos dedicados à análise rítmicas do livro de Van den Toorn (1987), e McDonald (2010), que propõe uma associação entre as organizações de alturas e rítmicas. Análises harmônicas e de relações de alturas são vistas nos últimos capítulos do livro de Van der Toorn (1987), bem como no livro de Forte (1978), que analisa a obra pelo prisma da teoria das classes de alturas. Taruskin (1980) mostra a apropriação de melodias do folclore russo feita por Stravinsky, e Craft (1966) e Smaley (1969-1970) examinam a concepção da obra sob a luz dos rascunhos deixados pelo compositor.

Nossa contribuição neste artigo se dá com a análise harmônica de Canope e da Introdução à primeira parte de $A$ Sagração da Primavera que mostra que, em ambas as peças, ocorre uma dissociação do plano de estruturação harmônica, de base tonal, da forma harmônica resultante (isto é, da resultante perceptual da harmonia dessas músicas) através de processos distintos e inerentes às técnicas de cada um dos compositores.

O restante do artigo divide-se em quatro partes: primeiramente, definimos o que entendemos pelos termos estrutura harmônica e forma harmônica, nas duas seções seguintes apresentamos, respectivamente, as análises harmônicas de Canope e do primeiro movimento (Introdução) de A Sagração..., para tecermos as considerações finais na última seção. 
Dissociação entre forma e estrutura harmônica em obras de Claude Debussy e Igor... Adriano Claro Monteiro

\section{Forma e Estrutura Harmônica}

Para este trabalho definimos dois conceitos: forma harmônica e estrutura harmônica.

Entendemos uma forma harmônica como uma resultante perceptual da harmonia de uma música. Esse conceito inclui, mas não se basta, à definição tradicional de forma em música como um seccionamento da obra no tempo. Nosso entendimento de 'forma' dialoga com a psicologia Gestalt, que entende forma por um objeto perceptual bem delineado, saliente em relação a um fundo, e que não pode ser reduzido à soma de suas partes. ${ }^{3}$ Portanto, uma forma harmônica que se escuta pode ser a qualidade percebida de um intervalo entre notas, de um acorde, de uma progressão harmônica, ou arcos e processos que guiam ou definem uma seção de uma obra. Um acorde de três notas em meio a uma textura musical complexa de muitas notas só obtém forma - enquanto objeto perceptual independente - se um outro atributo (ou um conjunto deles) o faz ser saliente em meio ao contexto de eventos sonoros, por exemplo, um timbre que o destaca ou uma diferenciação no registro. A simples simultaneidade das três notas, em meio à textura, não as fazem ganhar forma na escuta enquanto acorde destacado caso não haja heterogeneidade frente a um fundo mais homogêneo. De maneira similar, o entendimento de progressões de acordes só se torna saliente à percepção auditiva se requisitos para um fechamento da forma forem atendidos, como a integração temporal que permite a conexão entre os acordes em uma unidade. Intervalos de tempo muito longos entre os acordes de uma progressão e/ou a inserção de elementos harmônicos exógenos entre esses acordes podem inibir a inteligibilidade da progressão e, logo, da forma que dela resulta.

A estrutura harmônica é o conjunto de relações abstratas que definem as bases da organização harmônica de uma música ou de um trecho musical. A estrutura é preconcebida, é anterior ao ato

3 Mais aprofundamentos sobre confluência entre a psicologia Gestalt e a percepção musical podem ser vistos em Bregman (1990), Leman (1997), Temperley (2001). 
Dissociação entre forma e estrutura harmônica em obras de Claude Debussy e Igor... Adriano Claro Monteiro

de instanciação e delimita suas possíveis relações. Por exemplo, as estruturas harmônicas gerais ao estilo da música modal são: as alturas delimitadas aos graus (notas) dos modos, os tipos de acordes dados por relações intervalares em relação ao baixo, as possibilidades de condução de vozes (contraponto); para a música tonal são as qualidades de acordes em relação à nota fundamental, às relações hierárquicas entre acordes dos modos (maior e menor), os arcos de tensão/instabilidade e estabilidade delimitados por cadências (preferencialmente, cadências autênticas ( $\mathrm{V}^{7}$ - I)), a condução de vozes (contraponto). Podemos pensar também em estruturas específicas para uma obra: um planejamento harmônico para o arco expressivo de uma peça; uma progressão harmônica que se repete em uma passacaglia. Nesses casos, a forma harmônica é, então, o percepto resultante da instanciação sonora de escolhas composicionais locais: alturas, registro dessas alturas, progressões harmônicas e até mesmo os timbres associados e o equilíbrio de dinâmicas entre alturas.

Consideramos importante referenciar aqui uma noção similar de estrutura que foi introduzida por Heinrich Schenker (1977) e adotada pelos continuadores de sua abordagem analítica (KATZ, 1946; SALZER, 1952; FORTE, GILBERT, 1982). Em seus escritos, Schenker trata apenas da música tonal do período da prática comum e especialmente do repertório germânico. Para Schenker, toda obra tonal "bem realizada" ou "exemplar" é resumível em uma estrutura fundamental (Ursatz) que consiste em um contraponto a duas vozes sobre a tríade que define a tonalidade: uma voz superior em movimento descendente sobre os graus da tríade e em sentido à tônica; um baixo que realiza o arpejo sobre a mesma tríade começando e finalizando na nota fundamental (por exemplo, em sua manifestação mais simples seria: I-V-I). Ou seja, para Schenker, o desdobramento diacrônico e em movimento contrapontístico do arquétipo da tríade é a estrutura de toda obra tonal bem-sucedida. A elaboração da obra em elementos musicais se daria por camadas de 'prolongamentos' da estrutura fundamental através de técnicas de contraponto e ornamentações melódica e harmônica 
Dissociação entre forma e estrutura harmônica em obras de Claude Debussy e Igor... Adriano Claro Monteiro

que refletem as características da estrutura fundamental. É cara a Schenker essa concepção organicista de simetria e coerência entre as camadas de elaboração de uma obra, desde sua estrutura fundamental até a sua superfície musical (que se apresenta na partitura) (COOK, 1987). Autores schenkerianos expandem a noção de "tonalidade" para analisar obras pós-tonais elegendo estruturas fundamentais que não se baseiam apenas no arpejo da tríade, mas, sim, em movimentos melódicos e cadências típicos do contraponto modal (SALZER, 1952), ou em arpejos de arquétipos harmônicos não triádicos (TRAVIS, 1959; STRAUS, 1987; FORTE, 1988, VÄISÄLÄ, 2004). Mas, ainda para esses autores, as noções organicistas de simetria e coerência entre estrutura fundamental e superfície musical são preservadas como inerentes de uma obra bem-sucedida.

Dentro da corrente schenkeriana (incluindo para o próprio Schenker) a noção de forma musical é o tradicional seccionamento da obra em partes, mas que, para esses autores, se relaciona com os elementos da estrutura fundamental ou de prolongamentos dela. O que definimos como forma em nosso trabalho - elementos/unidades musicais perceptualmente salientes - seria mais próximo das consequências do "prolongamento" para os analistas schenkerianos, ou como algo como o conceito de "design" introduzido por Saltzer (1952, p. 224)

Apesar dessa proximidade no conceito de estrutura como algo subjacente à organização da obra e, não necessariamente, manifesto enquanto forma perceptiva, a concepção de estrutura que adotamos não busca um sistema de representação generalizável, como é o caso da schenkeriana. Especificamente em nossas análises de Canope e do movimento de Introdução de "A Sagração...", entendemos por estrutura harmônica uma progressão de funções harmônicas tonais que elucubramos que os respectivos compositores usaram como base para organizar suas músicas.

O que apontamos neste artigo é que, apesar de identificarmos nas obras de Debussy e Stravinsky estruturas harmônicas globais que se fundamentam em características do tonalismo, as formas 
Dissociação entre forma e estrutura harmônica em obras de Claude Debussy e Igor... Adriano Claro Monteiro

harmônicas resultantes na superfície musical operam como um recurso de mascaramento das características da estrutura e inibem uma possível relação auditiva com o esquema organizacional harmônico subjacente. O que vai em sentido oposto ao que ocorre na estética da música tonal propriamente (do período da prática comum), em que a superfície musical reflete as relações do sistema estruturante - como bem observa Schenker e os continuadores de seu trabalho. Em termos schenkerianos, seria dizer que nas peças de Debussy e Stravinsky analisadas neste artigo não há prolongamentos da estrutura fundamental para superfície das peças, ou que os prolongamentos não traçam uma relação coerente e orgânica com a estrutura.

Nas análises das duas obras a seguir a forma harmônica, por se tratar de uma característica fenomenológica, é abordada de uma maneira descritiva e é contextualizada com referências bibliográficas que mencionam aspectos semelhantes aos identificados por nossa análise auditiva. A análise da estrutura harmônica é feita por relações abstratas identificáveis nas partituras das obras.

\section{Análise de Canope}

\section{Seccionamento e Forma Harmônica}

As principais características musicais audíveis em Canope são as justaposições de coloridos triádicos com dissonâncias adicionadas, os motivos melódicos que se alternam com variações modais e cromáticas, mudanças acentuadas de registros e texturas. Notamos um jogo com os elementos da linguagem musical em "uma elaboração compositiva dedicada à expressão de uma estética muito precisa: uma estética que busca construir formas a partir da manipulação coordenada de componentes que agem diretamente sobre a sonoridade" (GUIGUE, 2011, p. 144). Guigue fala a respeito de uma constante na obra de Debussy: a forma harmônica 
Dissociação entre forma e estrutura harmônica em obras de Claude Debussy e Igor... Adriano Claro Monteiro

está em função das sonoridades momentâneas e de como elas se articulam, contrastam, interpolam, ou se transformam de um trecho a outro da peça, o que não é diferente no caso de Canope.

A análise apresentada por Hoffman (2002) aponta para o mesmo sentido. $\mathrm{O}$ autor divide Canope em nove segmentos (que ele chama de 'episódios') e classifica a forma como aditiva (entendendo aqui forma no sentido tradicional da divisão da obra em seções): “...um procedimento composicional no qual blocos sonoros pequenos, geralmente não relacionados, são colocados lado a lado ou sobrepostos para construir um todo maior, da mesma maneira como um artista cria um mosaico ou um pedreiro constrói uma parede"4 (HOFFMAN, 2002, p. 106), um tipo de organização musical que diverge do modelo de desenvolvimento por variações motívicas, cara à tradição ocidental, "o que para Schoenberg foi sintetizado na música de Wagner como 'modelo e sequência' e na de Brahms como 'variações em desenvolvimento'"'5 (HOFFMAN, 2002, p. 106). O autor observa que cada segmento do prelúdio contém um motivo melódico singular que é repetido duas vezes antes que se mude para o próximo, ainda que possa haver inclusões de elementos de transição.

A Tabela 1 mostra a divisão da obra proposta por Hoffman (2002), onde as letras maiúsculas na segunda linha da tabela são a nomenclatura para os diferentes segmentos e a primeira linha da tabela contém os números de compasso em que eles se localizam na peça. As letras repetidas e com apóstrofe significam variações de trechos anteriores. Hoffman (2002) identifica centros harmônicos momentâneos para os segmentos formais que classifica - momentos de polarização transitória em uma nota fundamental - sendo os centros harmônicos de B, C, D e E, respectivamente em Ré, Sol, Dó e Lá.

\footnotetext{
4 "... a compositional procedure in which small, often unrelated sound blocks are placed side by side or layered to build up a larger whole, much as an artist creates a mosaic or a stone mason constructs a wall".

5 “(...) what for Shoenberg was epitomized in Wagner's music as "model and sequence" and in Brahms' as "developing variation"'".
} 
Dissociação entre forma e estrutura harmônica em obras de Claude Debussy e Igor... Adriano Claro Monteiro

Tabela 1 - Divisão formal de Canope proposta por Hoffman (2002).

\begin{tabular}{|c|c|c|c|c|c|c|c|c|}
\hline C.1-6 & c.7-10 & c. 11-13 & c.14-15 & c.16-19 & c.20-23 & c.24-25 & c.26-29 & c.30-33 \\
\hline A & B & C & D & E & B' & F & A' & C' \\
\hline Ré & Ré & Sol & Dó & Lá & Ré & & Ré & Dó \\
\hline
\end{tabular}

Descrição: A primeira linha da tabela indica os compassos dos segmentos, a segunda linha os nomeia com símbolos alfabéticos e a terceira contém os centros harmônicos de cada segmento.

\section{Estrutura Harmônica}

Subjacente à forma harmônica de Canope com seus centros harmônicos transitórios, em nossa análise observamos uma estrutura harmônica de ambiguidade bitonal com centros em Ré menor e Dó maior. Esta análise pode ser visualizada no Exemplo 1 e na Tabela 2, que contêm, respectivamente, uma redução e um resumo da análise harmônica da peça6.

\section{Exemplo 1 - Redução da harmonia em Canope.}

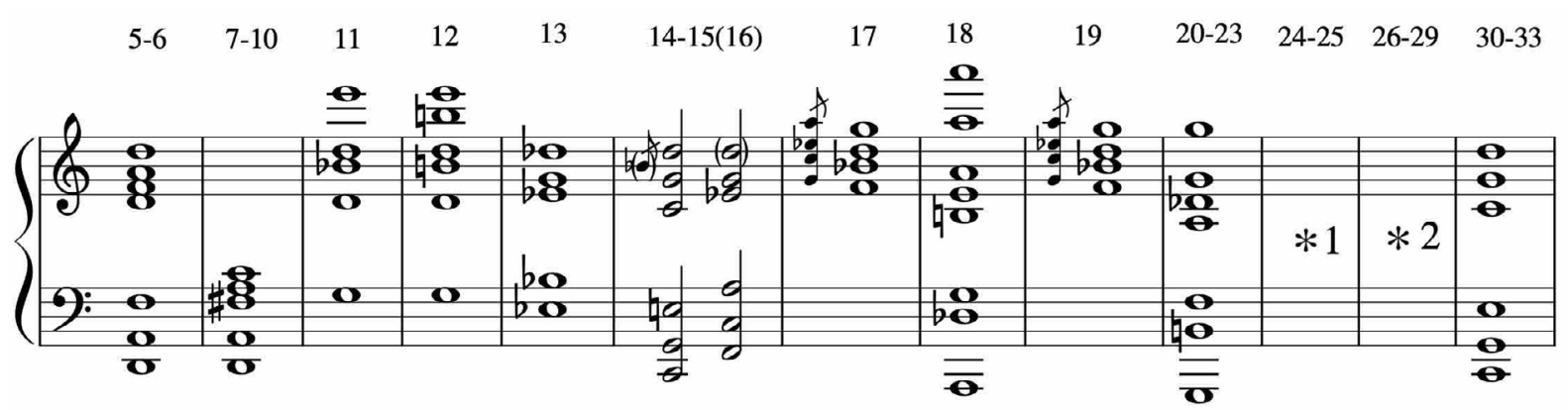

Os números acima da pauta indicam os compassos em que os acordes se encontram na partitura. Notas entre parênteses são incorporações da linha melódica à redução harmônica. Figuras de appoggiaturas indicam appoggiaturas na música que foram consideradas na redução harmônica. *1 e *2 são casos em que as reduções harmônicas são mais complexas e não podem ser reduzidas a simples verticalizações.

6 Utilizamos a nomenclatura de classificação harmônica através de algarismos romanos que identificam os graus da escala que são a fundamental dos acordes, bem como a qualidade das tríades, suas inversões e a inclusão de dissonâncias, tal qual é proposta por Kostka, Payne e Almén (2018), e Piston (1998). 
Dissociação entre forma e estrutura harmônica em obras de Claude Debussy e Igor... Adriano Claro Monteiro

Tabela 2 - Resumo da análise harmônica de Canope.

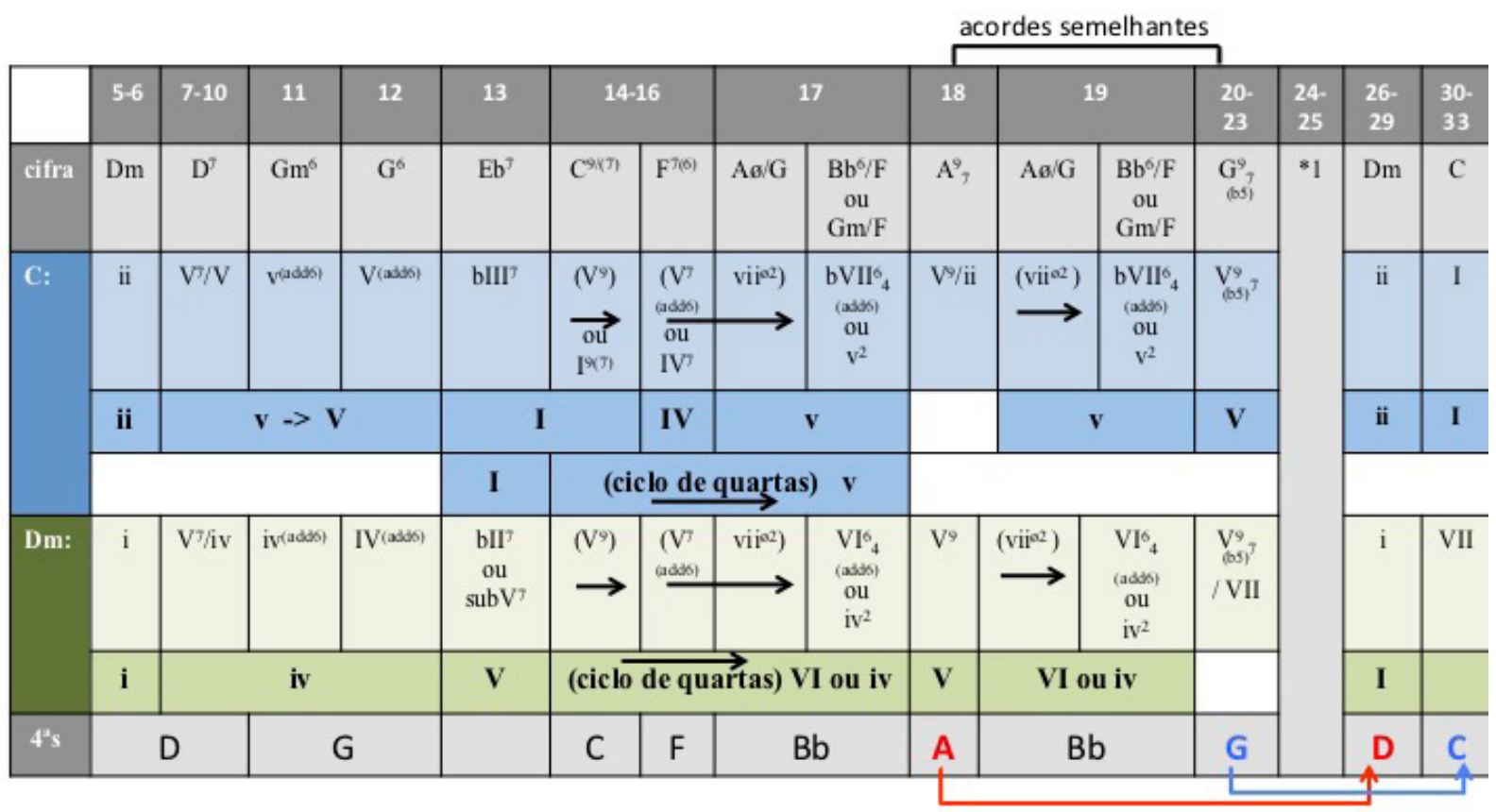

A primeira linha da tabela contém os compassos que circunscrevem cada mudança harmônica (divisão igual a do Exemplo 1). A segunda linda contém as cifras dos acordes que aparecem, respectivamente, em notação no Exemplo 1. A primeira zona intermediária da tabela, em azul, e a segunda zona intermediária, em verde, contêm análises da harmonia interpretadas respectivamente sob a tonalidade de Dó maior e Ré menor. A última linha da tabela contém uma interpretação da harmonia reduzida a um ciclo de quartas seguido de duas cadências intercaladas.

Ainda que a melodia da peça sugira em quase todos os momentos um centro em Ré com variações modais, a camada de acompanhamento não estabelece uma tonalidade ou modalidade evidente. O bitonalismo da peça não é expresso pela sobreposição de camadas de elementos musicais em diferentes tonalidades, mas sim pela ambiguidade de alguns dos acordes empregados a servir a duas estruturas tonais diacrônicas concomitantes.

A segunda linha da Tabela 2 contém as cifras dos acordes. Nas linhas inferiores estão as classificações harmônicas: da segunda à quarta linha, em azul, sob a tonalidade de Dó maior; na quinta e 
Dissociação entre forma e estrutura harmônica em obras de Claude Debussy e Igor... Adriano Claro Monteiro

sexta linhas, em verde, sob a tonalidade de Ré menor. As primeiras linhas da tabela de cada tonalidade, em cores mais claras, apresentam classificações para cada acorde. As linhas subjacentes, em cores mais escuras, apresentam uma classificação harmônica reduzida onde funções harmônicas próximas ou relacionadas, como dominantes individuais ou mudanças de qualidade maior-menor, são colocadas sob uma mesma classificação geral.

Ambas as reduções das estruturas harmônicas em Dó maior e Ré menor são compostas de funções harmônicas elementares como tônica, subdominante e dominante, ou funções relativas simples - o primeiro, segundo, quarto, quinto e sexto graus da respectiva escala diatônica. E ambas as estruturas terminam a música em cadências plagais.

A ambiguidade funcional dos acordes de G/Gm (Dominante em Dó (V) ou Subdominante em Ré (iv)) e Dm (Subdominante Relativa em Dó (ii) ou Tônica em Ré menor (i)) é determinante para essa interpolação entre as tonalidades estruturantes. Contudo, o principal pivô da ambiguidade bitonal na estrutura harmônica da peça é a relação entre os acordes dos compassos 18 e 20: o primeiro um A9/7 e o segundo um G9/7/b5. Esses acordes contêm as mesmas notas redistribuídas no registro (respectivamente: Lá, Ré bemol, Mi, Sol, Si; e Sol, Si, Ré bemol, Fá, Lá), com a exceção de uma alteração cromática de Mi para Fá. Ou seja, a dominante dos dois tons estruturantes Ré e Dó é praticamente o mesmo acorde com as notas redistribuídas no registro. Também é interessante notar que o acorde com fundamental em Sol é formado pela escala completa de tons inteiros se considerarmos a nota Mi bemol de appoggiatura. O Exemplo 2 mostra o trecho entre os compassos 18 e 20 em que esses acordes aparecem. 
Dissociação entre forma e estrutura harmônica em obras de Claude Debussy e Igor... Adriano Claro Monteiro

\section{Exemplo 2 - Compassos 18 ao 20 de Canope}

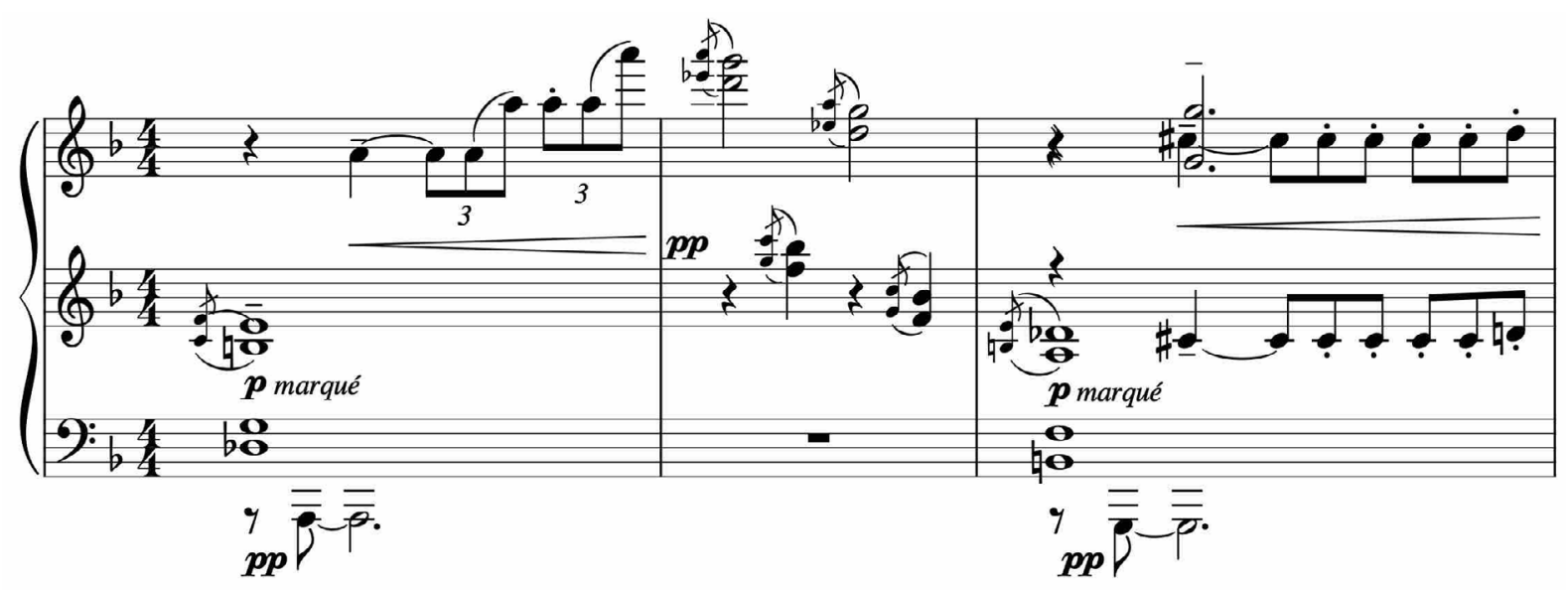

Debussy parece fazer uso consciente dessa semelhança ao enfatizá-la na forma da peça: os dois acordes estão a um compasso de distância na partitura, no ponto de transição entre o ápice dramático e de desenvolvimento da peça, que também é o momento em que há a maior quebra textural e a primeira recapitulação de material (do segmento B - vide Tabela 1). Além disso, o acorde de tons inteiros, o G9/7/b5, está localizado no início do compasso que mais se aproxima da proporção áurea em relação ao número total de compassos da peça. ${ }^{7}$

As dominantes das tonalidades estruturais são "resolvidas" na mesma ordem em que aparecem: o A9/7 é dominante da tonalidade de Ré menor da recapitulação da introdução; e o G9/7/ b5 é dominante do acorde final dos últimos compassos, Dó maior - como indicamos com as setas abaixo da Tabela 2. O tempo que separa esses acordes e a interpolação das duas progressões tornam a percepção dos movimentos cadenciais difusa (talvez a neutralizando completamente), isto é, essas cadências não se manifestam na forma harmônica, mas são pontos de articulação estruturais.

\footnotetext{
70 número total de compassos da peça é 33 e o acorde citado aparece no primeiro tempo do compasso 20 , logo, a proporção $33 / 20=1,65$ é intrigantemente próxima da razão áurea: 1,618. Hoffman (2002) também observa essa propriedade contextualizando-a à retomada do material temático e à localização do ápice expressivo da música. Apesar de não haver documentos que confirmem o interesse de Debussy em utilizar propriedades numéricas para estruturar sua música, Hoffman cita as correspondências entre o compositor e seu editor que levam a crer que tais relações poderiam existir, mesmo que de maneira sutil.
} 
Dissociação entre forma e estrutura harmônica em obras de Claude Debussy e Igor... Adriano Claro Monteiro

Esses acordes de dominante-sétima dos centros tonais estruturantes Dó e Ré são evitados até os compassos 18 e 20. Alusões a eles são feitas de maneira indireta ou menos assertivas, como o acorde G6 no compasso 12, dominante de Dó, ou o acorde de Eb7 no compasso 13, que compartilha enarmonicamente do mesmo trítono do acorde A7 (Ré bemol (Dó sustenido) - Sol), dominante de Ré, tendo então uma possível resolução por movimento cromático da sua fundamental Mi bemol ao Ré, e do trítono Ré bemol-Sol à terça Ré-Fá8. O acorde Eb7 também pode ser interpretado como uma incorporação à harmonia da sensível superior de Ré, que é utilizada repetidamente na melodia nos compassos que o precedem e no qual o acorde se encontra, nesse caso por relação enarmônica entre as notas Ré bemol e Dó sustenido. Ele poderia ser interpretado como acorde de sexta-aumentada do tipo germânico (Ger+6) com possível progressão para a dominante (D7) sob uma tonicização em Sol (compassos 11 e 12). Ou ainda, como uma resolução de cadência deceptiva (em Dó maior) para o acorde mediante inferior, um empréstimo do modo menor com adição da sétima menor, que posteriormente resolve na Tônica continuando o movimento por terças (ii - V7/V - v(6) - V(6) - bllI7 - 19). Porém, a inversão na força das dissonâncias - a sexta acrescentada no acorde de Sol Maior que antecede o Mi bemol maior, e a sétima menor deste último - enfraquece a progressão e descaracteriza o tom resolutivo do acorde. A interpretação da progressão em Ré menor ( $\mathrm{i}$ - V7/iv - iv(6)/IV(6) - SubV7) tem mais respaldo de linguagem e sonoridade, pois "a sexta acrescentada é tão característica da subdominante, como a sétima da dominante" (KOELLREUTER, 2018, p. 40).

O único movimento harmônico V7 - I direto que ocorre em toda a peça está na progressão do acorde D7 para Gm6 entre os compassos 10 e 11; contudo o movimento cadencial não é confirmado pelas características melódicas, rítmicas e texturais dessa passagem. Estruturalmente, essa progressão pode ser interpretada como a resolução de uma dominante secundária: dominante da

$\overline{80}$ acorde de dominante distante meio tom acima do acorde em que é resolvido é denominado por alguns métodos de harmonia da música popular como 'dominante substituta' - sigla SubV (GEST, 2009, p. 78-80). 
Dissociação entre forma e estrutura harmônica em obras de Claude Debussy e Igor... Adriano Claro Monteiro

subdominante, na tonalidade de Ré, ou dominante da dominante, na tonalidade de Dó. As demais resoluções de acordes dominante-sétima que caracterizariam as tonalidades estruturantes da música são deceptivas, como de Eb7 para C (compassos 13 e 14); A9/7 para Bb6 (compassos 18 e 19); G9/7/b5 para Dm (compassos 22 e 23). Ao evitar a percepção direta das progressões de acordes que caracterizam cadências tonais, alongando-as no tempo, introduzindo acordes intermediários, substituições cromáticas, e adicionando dissonâncias estranhas às qualidades funcionais dos acordes em determinado contexto, Debussy dissocia o plano estrutural harmônico da forma harmônica da peça. Essa característica é ainda reforçada pelas constantes alterações súbitas da textura e do registo (alterações de ordem timbrística) associadas às mudanças de acordes.

Uma segunda interpretação para a estrutura harmônica da peça está resumida na última linha da Tabela 2. Nela, a progressão de acordes, ou de centros harmônicos temporários, é construída sobre um ciclo de quartas a partir do Ré até o Si bemol do compasso 17, seguido das duas cadências em Dó maior e Ré menor intercaladas. As figuras em torno dos compassos 17 e 19 têm um interesse particular: apresentam o maior contraste textural; são os únicos trechos em que os acordes não estão em posição fundamental; e há no compasso 17 uma mudança de andamento para Animez un peu. A inversão dos acordes de $\mathrm{Bb} 6$ deixa-os ambíguos em relação a Gm7. Tais características, junto aos acordes similares de dominante A9/7 e G9/7/b5 descritos acima, sinalizam o clímax formal e estrutural da peça entre os compassos 17 e 23 . As figuras de appoggiatura do compasso 16 são uma ponte para o início desse trecho, bem como as figuras dos compassos 24 e 25 o são para a recapitulação do material do início da peça.

O símbolo *1 na Tabela 2 diz respeito ao material da segunda ponte, um trecho em que podemos extrair pouca relação com o restante da análise harmônica da peça. $\mathrm{O}$ extrato desse trecho está no Exemplo 3. 
Dissociação entre forma e estrutura harmônica em obras de Claude Debussy e Igor... Adriano Claro Monteiro

\section{Exemplo 3 - Compassos 23 ao 25 de Canope}

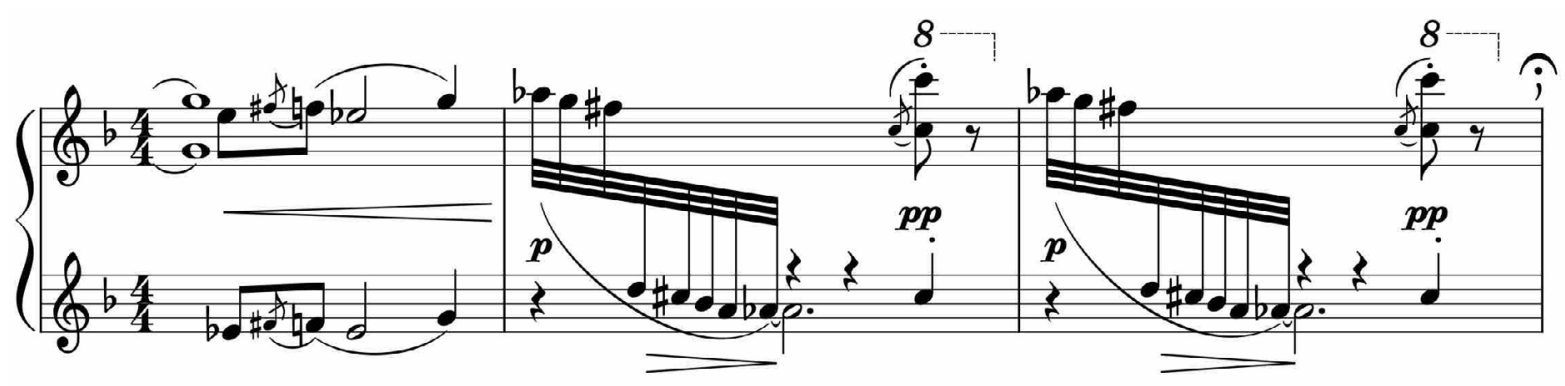

Pode-se dizer que as notas de maior duração dos compassos 24 e 25 formam uma tríade de Lá bemol maior, porém, isso tem pouca relação com os centros tonais ou com a sequência do ciclo de quartas. De fato, as notas Dó e Mi bemol, enfatizadas no quarto tempo de cada compasso, são alturas importantes no decorrer da obra. O Mi bemol, em especial, é recorrente como sensível superior para o Ré nos motivos melódicos e nesse trecho tem a mesma função para a retomada do material inicial em Ré. A formação escalar do gesto descendente no início de cada compasso explora cromatismos espaçado por intervalos de terças, mas isso não aponta uma relação forte com outros elementos da peça.

Finalmente, cabe olhar o material dos quatro primeiros compassos (Exemplo 4) que se repete de forma variada nos compassos 26 a 29 (Exemplo 5, designado com símbolo *2 no Exemplo 1). Hoffman (2002) analisa diversas relações de correspondência entre o material desse trecho e elementos harmônicos da peça. Nossa análise também traça algumas relações nesse sentido, porém diferentes das observadas por Hoffman.

\section{Exemplo 4 - Compassos 1 ao 4 de Canope}

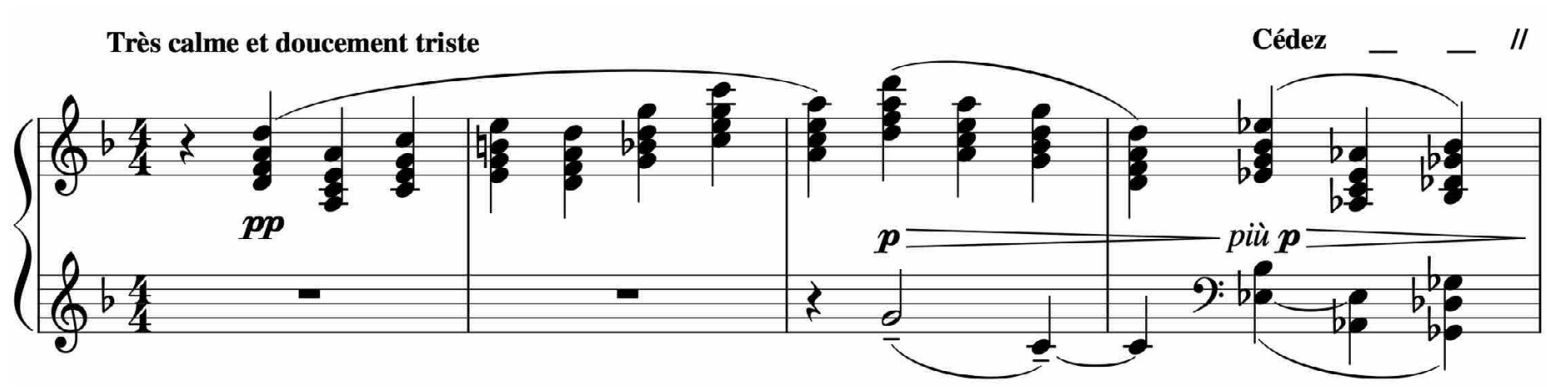


Dissociação entre forma e estrutura harmônica em obras de Claude Debussy e Igor... Adriano Claro Monteiro

Exemplo 5 - Compassos 29 ao 29 de Canope

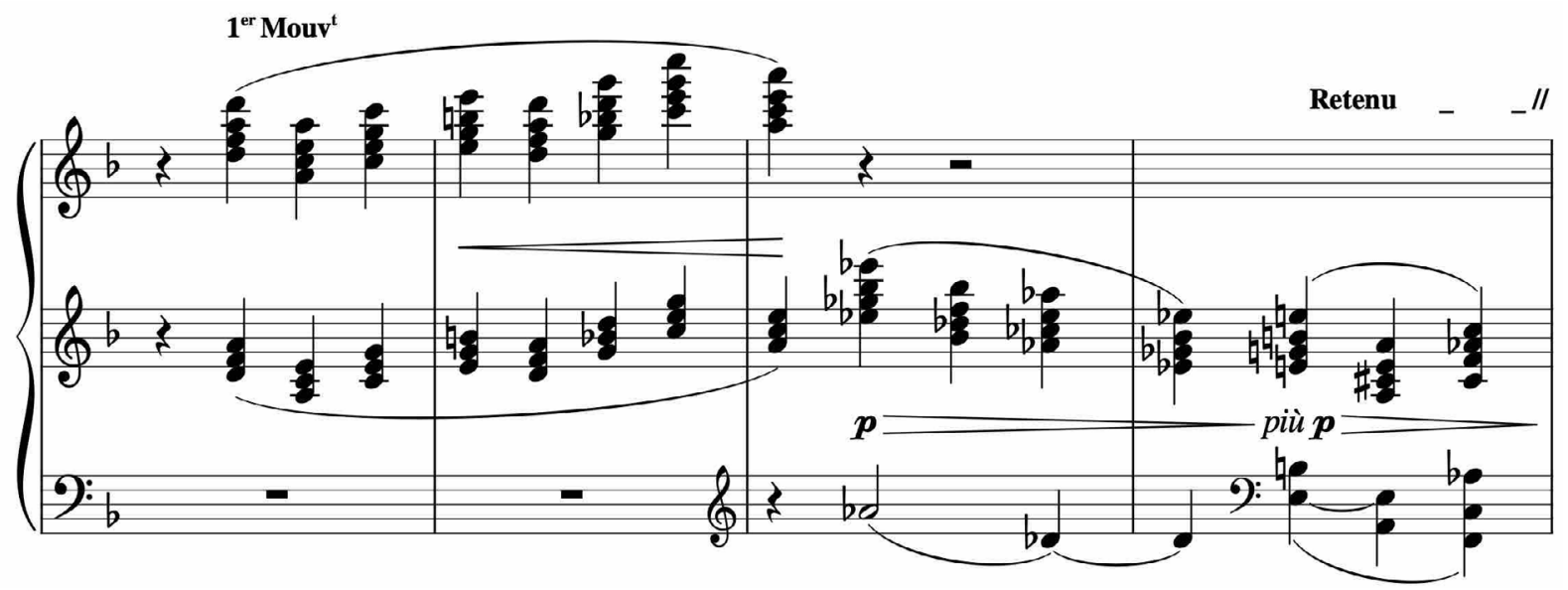

Segundo nossa compreensão, algumas relações estruturais na harmonia da peça aparecem implicadas nessa introdução. A armadura de clave indica a tonalidade de Ré menor (um dos tons estruturantes da peça, como demonstramos acima), porém o início da progressão de acordes paralelos que formam uma melodia pentatônica enfatizam o modo Ré dórico e, logo, remetendo à escala de Dó maior. O intervalo Sol - Dó (V e I da tonalidade de Dó) na pauta inferior no terceiro compasso, síncrono à cadência plagal em Ré menor na pauta superior, indica uma sobreposição das cadências em Ré menor e Dó (maior). Não nos é aparente nenhum outro motivo que justificaria a inclusão da sequência de duas notas (Sol e Dó) que não seja uma espécie de síntese dos elementos de importância na composição da obra, remetendo à ambiguidade estrutural das tonalidades em Ré e Dó que demonstramos na análise.

Outra relação importante a ser observada nessa passagem é a alteração cromática que ocorre a partir do segundo tempo do quarto compasso que "bemoliza" notas da sequência de tríades $\mathrm{Em}$ - Am - Gm, transformando-as em $\mathrm{Eb}-\mathrm{Ab}-\mathrm{Gb}$. A sensível superior de Ré (Mi bemol) é um elemento importante na construção melódica e harmônica da peça, além disso, a ordem com que os cromatismos são inseridos no trecho (Si bemol - Mi bemol - Lá bemol - Ré bemol - Sol bemol) remete ao ciclo de quartas que também é estrutural na progressão harmônica do restante da 
Dissociação entre forma e estrutura harmônica em obras de Claude Debussy e Igor... Adriano Claro Monteiro

obra, como demonstramos anteriormente, porém aqui com notas distintas.

Na retomada do tema inicial, nos compassos 26 a 29 (vide Exemplo 5), a transposição meio tom acima ocorre a partir do segundo tempo do terceiro compasso. Os três últimos acordes são transpostos então pela segunda vez e acumulam uma transposição de um tom em relação a escala de Ré menor. Por essa lógica, o último acorde deveria ser um Gm, contudo Debussy alterou-o para Fm, talvez para reforçar a cadência de tipo plagal que é recorrente na peça e que aqui se configura entre o Fm e o acorde final C.

\section{Análise do Movimento de Introdução de $A$ Sagração Primavera}

\section{Seccionamento e Forma Harmônica}

A característica mais marcante no movimento de Introdução da primeira parte de A Sagração da Primavera é a sobreposição de motivos melódicos solistas com traços modais ou cromáticos. Não se pode atribuir com clareza um modo específico às melodias escritas por Stravinsky na Introdução, pois quase nunca os modos são apresentados integralmente ou eles contêm variações cromáticas em seus graus. Com centros harmônicos distintos, a sobreposição dessas melodias resultam em uma sonoridade cromática e dissonante. Em alguns trechos da música a textura é puramente polifônica, em outros é acompanhada por notas sustentadas ou por figurações melódicas menos proeminentes que realizam o preenchimento harmônico e textural da peça. Há pouco desenvolvimento motívico ou temático no sentido clássico-romântico tradicional. A forma global da peça é guiada majoritariamente por um jogo de contrastastes, cortes e repetições, assim como por um processo de acúmulo e adensamento textural. As marcações de ensaio na partitura orquestral (STRAVINSKY, 2000) ajudam a entender a forma do movimento delimitando-a em doze segmentos. Na maioria das vezes os segmentos contíguos contrastam em 
Dissociação entre forma e estrutura harmônica em obras de Claude Debussy e Igor... Adriano Claro Monteiro

instrumentação, textura e harmonia, e as articulações formais entre eles são cortes ou interpolações de materiais.

Entendemos a macro-forma da Introdução em três grandes seções:

I) do início até a marcação de ensaio $n^{\circ}$ 3: tipos melódicos se alternam - melodia sugerindo o modo de Lá menor, melodia cromática, melodia sugerindo Dó sustenido menor. Nesse trecho são introduzidos dois dos principais motivos melódicos reiterados ao longo da peça.

II) entre as marcações de ensaio $n^{\circ} 4$ e $n^{\circ}$ 9: novos motivos melódicos solistas são gradativamente introduzidos ou reiterados. As passagens de um segmento a outro são marcadas por mudanças harmônicas e texturais abruptas.

III) entre as marcações de ensaio $n^{\circ} 10$ e $n^{0} 12$ : junto à sobreposição dos motivos solistas que foram introduzidos nos segmentos anteriores há um progressivo adensamento textural em direção ao tutti. O ápice dramático desse processo acontece no final do segmento $n^{\circ} 11$ e termina com um corte seguido de uma retomada modificada da melodia do início da peça - um solo desacompanhado tocado pelo fagote no segmento $\mathrm{n}^{\circ} 12$.

\section{Estrutura Harmônica}

Harmonicamente, podemos observar na Introdução as técnicas que são características das fases nacionalista e neoclássica de Stravinsky, assim como para outros compositores que compartiIharam a sua geração e alinhamento estético (KOSTKA e SANTA, 2018, p. 17-104; TUREK, p. 279-371). São recursos que resultam em sonoridades cromáticas sem abandonar os elementos arquetípicos da tradição ocidental, por exemplo: o uso de escalas e modos exóticos aos arquétipos maior/menor, como escalas de tons inteiros e octatônica; dissonâncias acrescentadas às sonoridades triádicas; inclusão de notas meio-tom de distância de uma 
Dissociação entre forma e estrutura harmônica em obras de Claude Debussy e Igor... Adriano Claro Monteiro

ou mais notas que compõem um acorde; sobreposição de tríades ou tétrades.

A análise que apresentamos a seguir aponta que Stravinsky parece fazer uso de uma estrutura harmônica simples e baseada em uma progressão de funções tonais simples (Tônica, Dominante e Subdominante) que, através das técnicas descritas no parágrafo anterior, é subvertida na forma harmônica altamente cromática e com melodias de intenção que ouvimos na obra.

Analisamos as relações harmônicas que se dão a cada segmento da peça. O Exemplo 6 contém a redução harmônica para cada segmento indicado pelas marcações de ensaio na partitura e a Tabela 3 contém uma descrição analítica do mesmo conteúdo.

Os segmentos iniciais de 0 a 3 e o segmento 9 são estritamente polifônicos e, portanto, a classificação harmônica foi derivada das qualidades das escalas ou modos sugeridos pelas melodias. O modo de Dó sustenido menor dos segmentos 2 e 3 é extraído de variações de um mesmo motivo melódico que no segmento 2 tem sonoridade pentatônica com centro em Ré sustenido (vide Exemplo 7.A), e no segmento 3 Stravinsky acrescenta a nota Mi ( $3^{\mathrm{a}} \mathrm{m}$ de Dó sustenido), deixando a entender o uso do pentacorde inicial de Dó sustenido eólio, apesar do centro da melodia permanecer em Ré (vide Exemplo 7.B).

Exemplo 6 - Redução harmônica da Introdução à primeira parte de $A$ Sagração da Primavera a cada segmento delimitados pelas marcações de ensaio na partitura de orquestra.
0
1
2034
5
$6 \quad 7$
8
9
10 e 11
12

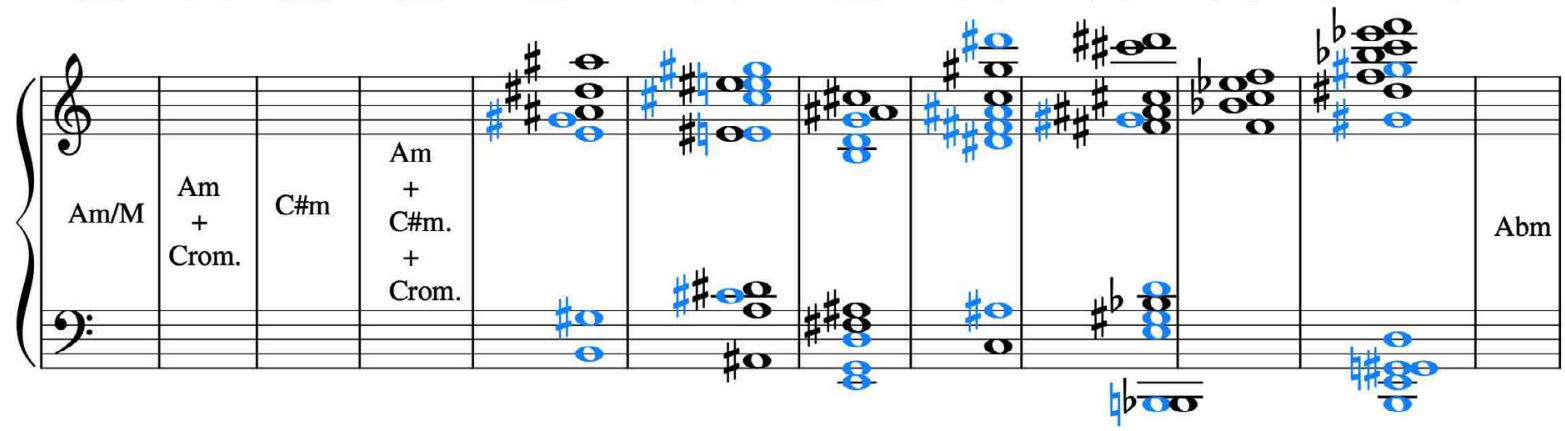


Dissociação entre forma e estrutura harmônica em obras de Claude Debussy e Igor... Adriano Claro Monteiro

Números acima da pauta. O número 0 é adicionado aqui para o início da peça até a marcação 1.

Mesmo sendo indiscutivelmente polifônico, classificamos duas das melodias do segmento 9 como uma formação vertical (acorde), pois ela deriva de um arpejo do acorde F7 com a $4^{\mathrm{a}}$ justa substituindo a $3^{a}$ (F7 (sus4)), ou da inversão de um acorde obtido por sobreposição de intervalos de quartas justas com início na nota Dó (vide Exemplos 7.F e 7.G).

Tabela 3 - Descrição analítica da Introdução à primeira parte de $A$ Sagração da Primavera

\begin{tabular}{|c|c|c|c|}
\hline Segmento & $\begin{array}{l}\text { Relações verticais: } \\
\text { Tríades/tétrades principais }\end{array}$ & $\begin{array}{l}\text { Dissonâncias } \\
\text { adicionadas }\end{array}$ & $\begin{array}{l}\text { Relação horizontais: } \\
\text { (escalas ou modos) }\end{array}$ \\
\hline 0 & & & $\begin{array}{l}\text { Melodia: Lá menor } \\
\text { (eólio) }\end{array}$ \\
\hline 1 & & & $\begin{array}{l}\text { Melodia; Lá menor } \\
\text { (eólio) + escala } \\
\text { cromática }\end{array}$ \\
\hline 2 & & & Dó sustenido menor \\
\hline 3 & & & $\begin{array}{l}\text { Melodia: Lá menor } \\
\text { (eólio) + Dó sustenido } \\
\text { menor (eólio) + escala } \\
\text { cromática }\end{array}$ \\
\hline 4 & $\mathrm{E}$ & $7 \mathrm{M}, 4$ aum & \\
\hline 5 & $\mathrm{~A}^{7 \mathrm{M}}+\mathrm{A} \# \mathrm{~m}^{7}$ & & \\
\hline 6 & $\mathrm{Em}^{7}+\mathrm{F} \#$ & & \\
\hline 7 & $\mathrm{D} \# \mathrm{~m}$ (ou $\mathrm{Ab}^{7}$ enarm.) & $\begin{array}{l}\text { 7dim, 11J (ou } \\
9 \mathrm{M} \text { enarm.) }\end{array}$ & $\begin{array}{l}\text { Melodia: Ré menor } \\
\text { (eólio) }\end{array}$ \\
\hline 8 & $\mathrm{E}^{7}+\mathrm{D} \# \mathrm{~m}^{7}$ & & $\begin{array}{l}\text { Melodia: Ré menor } \\
\text { (eólio) - mixolídio }\end{array}$ \\
\hline 9 & $\begin{array}{c}\mathrm{F}^{7 \text { (sus } 4 \text { ) }} \\
\text { (ou acorde quartal: Dó-Fá-Si } \\
\text { bemol- Mi bemol) }\end{array}$ & $4 \mathrm{~J}$ & Melodia: Ré mixolídio \\
\hline 10 e 11 & $\mathrm{~F}^{7(\mathrm{sus} 4)}+\mathrm{EM} / \mathrm{m}^{7}$ & & \\
\hline 12 & & & $\begin{array}{l}\text { Melodia: Lá bemol } \\
\text { (eólio) }\end{array}$ \\
\hline
\end{tabular}


Dissociação entre forma e estrutura harmônica em obras de Claude Debussy e Igor... Adriano Claro Monteiro

Primeira coluna: segmento de acordo com número de ensaio; segunda coluna: cifras dos acordes estruturais; terceira coluna (em azul no Exemplo 6): dissonâncias adicionadas como intervalos; quarta coluna: modo das melodias.

Nos segmentos 4, 5, 6, 7, 8, 10 e 11 reduzimos as relações harmônicas a acordes, pois as texturas são predominantemente homofônicas e uma considerável parte das melodias e das figuras diacrônicas contêm poucas notas em forma de arpejos. Dos complexos acordes obtidos observamos tríades ou tétrades de base (assinaladas pelas notas de cor azul no Exemplo 6, e na segunda coluna da Tabela 3), e as dissonâncias que Ihes foram acrescentadas (na terceira coluna da Tabela 3). Em geral, as dissonâncias acrescentadas são notas a meio tom ou a um tom de distância de uma ou mais notas que compõem os acordes principais. Nos segmentos 5, 6, 10 e 11 essas relações chegam a formar a sobreposição de dois acordes completos, que são sinalizados na segunda coluna da Tabela 3 após o símbolo de soma (+). 
Dissociação entre forma e estrutura harmônica em obras de Claude Debussy e Igor... Adriano Claro Monteiro

Exemplo 7 - Exemplos de alguns dos motivos melódicos da Introdução da primeira parte de $A$ Sagração da Primavera.

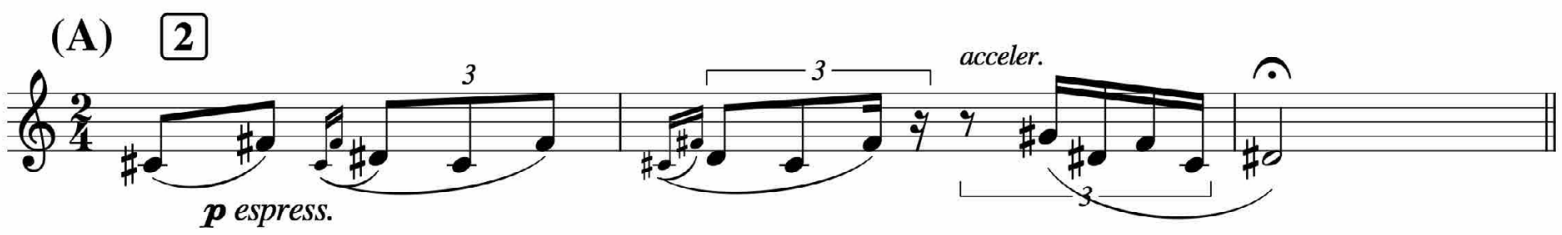

(B) 3
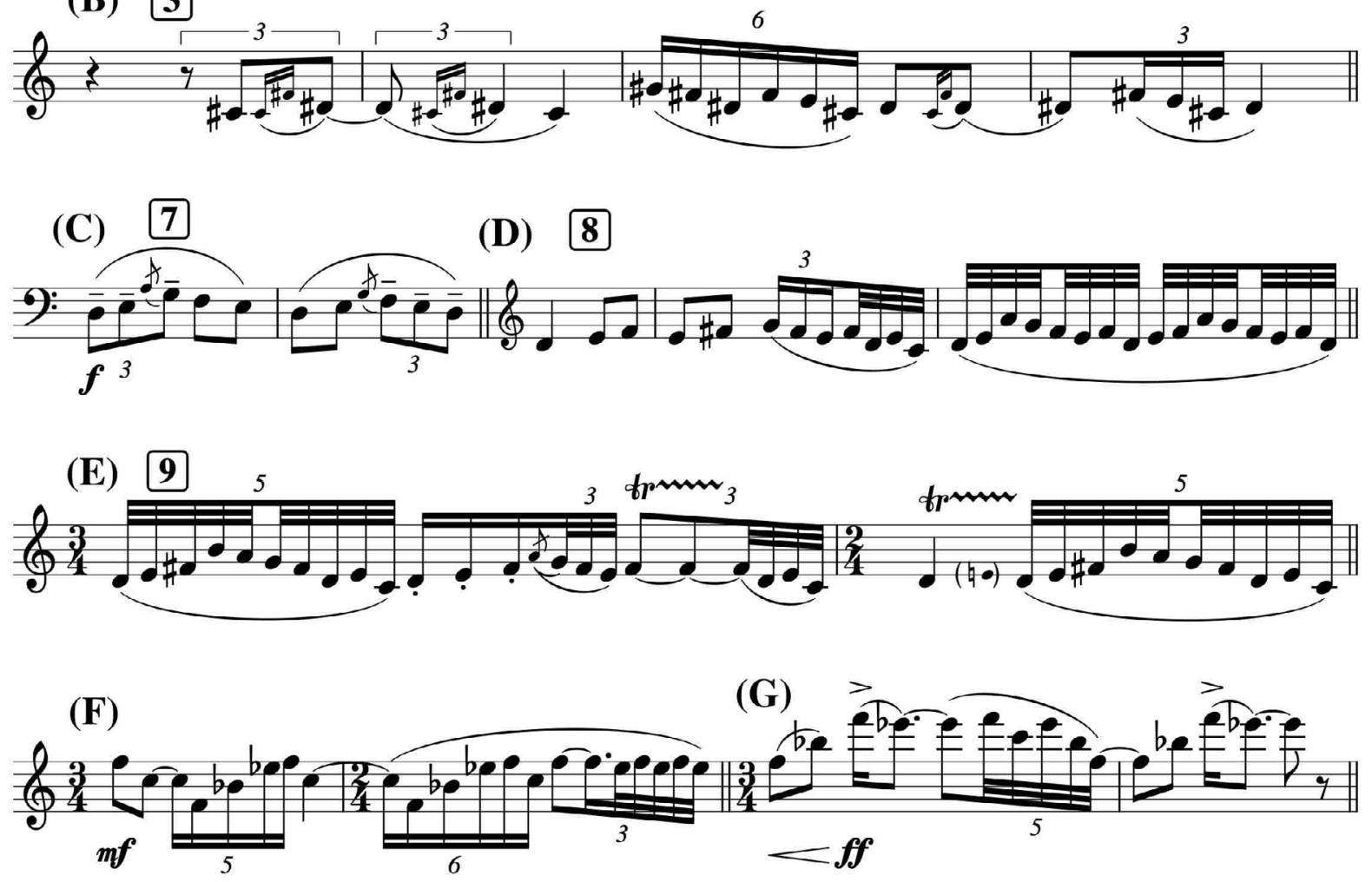

As letras e barras duplas separam diferentes motivos. Os números inseridos em quadrados designam os segmentos da peça em que os motivos estão inseridos, de acordo com as marcações de ensaio.

A interpretação analítica que queremos salientar neste trabaIho é a estrutura de centros harmônicos que Stravinsky utiliza a partir dos acordes de base mencionados no parágrafo anterior. Três centros são recorrentes: Lá, Mi e Ré. Lá menor é o modo sugerido na melodia inicial que se estende até o segmento 3, alternando com apresentações do motivo no modo de Dó sustenido menor (relativo menor de Mi maior), e também está presente no 
Dissociação entre forma e estrutura harmônica em obras de Claude Debussy e Igor... Adriano Claro Monteiro

segmento 5 junto à sobreposição de um acorde meio tom acima. Os segmentos 4, 6, 8, 10 e 11 enfatizam E7 com alterações de sonoridade típicas da técnica de Stravinsky: acréscimo de dissonâncias, alteração da qualidade maior ou menor, sobreposições de acordes com defasagem de meio ou um tom (D\#m, F7(sus4) ou F\#). Os segmentos 7 e 9 contêm apenas os acordes com distância de meio tom em relação ao E7 (D\#m e F7(sus4), respectivamente); ainda que o segmento 7 possa ser interpretado enarmonicamente como um Ab9/7, e o segmento 9 como um acorde de sobreposição de quartas invertido, a ênfase nas notas Ré sustenido e Fá fica notório pelos dobramentos e pela posição delas no registro.

O centro em Ré é menos enfático do que o arco I - V - I implícito nos centros harmônicos dos segmentos, conforme mostrado acima. Nos segmentos 7, 8 e 9, Ré é a tônica do modo sobre o qual um dos motivos melódicos mais recorrentes e mais desenvolvido/variado (Boulez, 1968, p. 137-138) é construído. Primeiramente aparece em modo menor (eólio) (vide Exemplo 7.C) para posteriormente ser variado para o modo mixolidio (vide Exemplos 7.D e 7.E). Essa melodia em Ré é sobreposta à harmonia que ocorre nos respectivos segmentos.

No segmento 12, Stravinsky recapitula a icônica melodia inicial da abertura da "Sagração..." ao fagote, porém, ao invés de retomá-la no modo original, em Lá menor, o compositor a transpõe meio-tom abaixo, em Lá bemol menor.

Portanto, Stravinsky parece fazer uso de uma estrutura harmônica simples e baseada em uma progressão de funções principais da música tonal (Tônica, Dominante e Subdominante): i - V - I -V (iv-IV) - bi ; que seria Am - E - A - E (Dm-D) - Abm, e que é subvertida em uma forma harmônica altamente cromática através das técnicas de sobreposição e alteração cromática apontadas acima. 
Dissociação entre forma e estrutura harmônica em obras de Claude Debussy e Igor... Adriano Claro Monteiro

\section{Discussão e Considerações Finais}

Neste artigo mostramos que ambas as peças analisadas: Canope - Prelúdio X, Livro II - de Claude Debussy, e a Introdução à primeira parte do balé $A$ Sagração da Primavera de Igor Stravinsky, possuem uma dissociação entre seus planos harmônicos estrutural e formal. A estrutura harmônica de ambas as obras se vale de um planejamento baseado nos arquétipos da harmonia tonal: progressões por funções principais de Dominante, Subdominante e Tônica. Porém, a forma resultante não torna sensível estas relações estruturais. Os compositores, cada um a seu modo, fazem com que a sonoridade harmônica resultante seja divergente: Debussy cria uma sonoridade com traços modais e certa independência dos coloridos dos acordes; já Stravinsky obtém uma sonoridade vertical cromática e bastante dissonante, com elementos horizontais (melodias) com traços predominantemente modais.

É importante ressaltar que seria pouco coerente pressupor que uma estrutura abstrata de planejamento por si só justificaria classificar essas obras como tonais, uma tendência estética e histórica que se valeu da objetividade perceptiva como origem e legitimação de suas elaborações teóricas. O que nossa análise leva a especular é que possivelmente Debussy e Stravinsky se valeram de arquétipos da música tonal para o planejamento de uma estrutura de base para a organização harmônica da peça, sobre a qual construíram sonoridades desviantes da tonalidade. É coerente pensar que nos primeiros anos do século XX, quando o sistema tonal era a base de formação dos compositores e a estética romântica estava bastante presente, o uso de recursos da tradição era um forte ponto de partida para o pensamento composicional, mesmo para o especulativo da época.

Ambas as músicas foram compostas nos primeiros anos da década de 1910, publicadas e estreadas no ano de 1913. Os compositores compartilhavam nesse período o ambiente artístico parisiense e é sabido que mantinham contato pessoal. Debussy havia 
Dissociação entre forma e estrutura harmônica em obras de Claude Debussy e Igor... Adriano Claro Monteiro

até mesmo tocado junto a Stravinsky a primeira metade da redução para piano à quatro mãos de $A$ Sagração... em junho de 1912 (HILL, 2000, p. 13). Entretanto, não há subsídio para afirmar que existe entre essas composições alguma influência mútua direta, seja de Debussy para Stravinsky ou vice-versa. O mais sensato a constatar é que nas peças transparece uma tendência estética e técnica da época no ambiente da vanguarda modernista parisiense. Futuros estudos de peças anteriores e posteriores de ambos compositores, bem como das obras de outros compositores que participavam do círculo musical parisiense da época, ajudarão a entender melhor essa relação.

\section{Referências}

BOULEZ, Pierre. Notes of an Apprenticeship. New York: Alfred A. Knopf, Inc. 1968. 398 p.

BREGMAN, Albert S. Auditory Scene Analysis: The Perceptual Organization of Sound. Cambridge: The MIT Press, 1994.

CHEONG, Wai L. The Rite of Spring: Rhythmic Rebirths as Delivered by Messiaen and Boulez. In: SICHARDT, Martina; HUST, Christoph; RORA, Contanze. Zeitgestalten - Zeit gestalten: Festschrift für Gesine Schröder zum 60. Geburtstag. Georg Olms Verlag, 2019, 353 p.

CODE, David. J. The Synthesis of Rhythms: Form, Ideology, and the "Augurs of Spring". The Journal of Musicology, v. 24, n. 1, p. 112-166, 2007.

COOK, Nicolas. Schenkerian Analysis. IN: A Guide to Musical Analysis. New York: Norton \& Company, 1987.

CRAFT, Robert. The Rite of Spring: Genesis of a Masterpiece.

Perspectives of New Music, v. 5, n. 1, p. 20-36, 1966.

DEBUSSY, Claude. Preludes pour Piano (2e Livre). Paris: Durand e Cie, 1913. 
Dissociação entre forma e estrutura harmônica em obras de Claude Debussy e Igor... Adriano Claro Monteiro

FAUSER, Annegret. Le sacre du printemps: a Ballet for Paris. IN: NEFF, S.; CARR, M.; HORLACHER, G.G. The Rite of spring at 100. Indiana University Press, Bloomington, 2017.

FORTE, Allen. New Approches to Linear Analysis of Music. Journal of the American Musicological Society, v. 41, n. 2, p. 315-348, 1988.

FORTE, Allen; GILBERT, Steven. Introduction to Schenkerian Analysis. New York: Norton \& Company, 1982.

GRIFFTHS, Paul. A música moderna: uma história concisa e ilustrada de Debussy a Boulez. Trad. Clovis Marques, Rio de Janeiro: Jorge Zahar, 1998, 202 p.

GUEST, Ian. Harmonia: método prático, volume 1. Lumiar, 2009. 163 p. GUIGUE, Didier. Estética da Sonoridade: A Herança de Debussy na Música para Piano do Século XX. São Paulo: Ed. Perspectiva, 2011. 424 p. HILL, Peter. Stravinsky: The Rite of Spring. Cambridge: Cambridge University Press, 2000. 184 p.

HOFFMAN, Richard. Debussy's Canope as Narrative Form. COLLEGE MUSIC SYMPOSIUM, v. 42, College Music Society, 2002. p. 103-117. KATZ, Adele. Challenge to Musical Tradition: A New Concept of Tonality. New York: Alfred Knopf, 1946.

KOELLREUTTER, Hans-Joachim. Harmonia Funcional: introdução à teoria das funções harmonicas. São João Del Rei: Fundação Koellreutter, 2018. 97 p.

KOSTKA, Stefan; PAINE, Dorothy; ALMÉN, Byron. Tonal Harmony with and introduction to post-tonal Music. 8th Ed. New York: Routledge, 2018. 337 p.

KOSTKA, Stefan; SANTA, Matthew. Materials and Techniques of Posttonal Music. 5th Ed. New York: McGraw-Hill Education, 2018. 681 p.

LEMAN, Marc (Ed.) Music, Gestalt, and Computating: Studies in Cognitive and Systematic Musicology. Berlin: Springer, 1997.

MCDONALD, Matthew. Jeux de Nombres: Automated Rhythm in The Rite of Spring. Journal of the American Musicological Society, v. 63, n. 3, p. 499- 551, 2010. 
Dissociação entre forma e estrutura harmônica em obras de Claude Debussy e Igor... Adriano Claro Monteiro

MESSIAEN, Olivier. Traité de rythme, de couleur, et d'ornithologie: Tome II. Paris: Alphonse Leduc \& Cia Editions Musicales, 1995. 530 p. NEFF, Severine.; CARR, Maureen.; HORLACHER, Gretchen.G. The Rite of spring at 100. Indiana University Press, Bloomington, 2017.

PISTON, Walter. Armonía. Cooper City: SpanPress, Inc. 1998. 550 p. SALZER, Felix. Structural Hearing: Tonal Coherence in Music. New York: Charles Boni, 1952

SCHENKER, Heinrich. Free Composition. (Trad. Oster, Ernst). Hillsdale: Pendragon Press, 1977.

SMALLEY, Roger. The Sketchbook of the Rite of Spring. Tempo, n. 91, p. 2-13, 1969-1970.

STRAVINSKY, Igor. The Rite of Spring. Rev. Ed. 1967. London: Boosey \& Hawkes, 2000.

STRAUS, Joseph. The Problem of Prolongation in Post-Tonal Music. Journal of Music Theory. v. 31, n. 1, p. 1-21, 1987.

TARUSKIN, Richard. Russian Folk Melodies in "The Rite of Spring". Journal of the American Musicological Society, v. 33, n. 3, p. 501-54, 1980.

TEMPERLEY, David. The Cognition of Basic Musical Structures. Cambridge: The MIT Press, 2001.

TUREK, Ralph. The Elements of Music: Concepts and Applications, v. 2. 2nd Edition. The MacGraw-Hill Companies, Inc. 1996. 498p.

TRAVIS, Roy. Towards a New Concepto of Tonality? Journal of Music Theory, v. 3, n. 2, p. 257-284, 1959.

VÄISÄLÄ, Olli. Prolongation in Early Post-Tonal Music: Analytical Examples and Theoretical Principles. Tese. Helsinki Sibelius Academy: Department of Composition and Music Theory, 2004.

VAN DEN TOORN, Pieter. C. Stravinsky and the Rite of Spring: The Beginnings of a Musical Language. Berkeley and Los Angeles: University of California Press, 1987.

WILLIAMS, James K. Theories and Analysis of Twentieth-Century Music. Harcourt Brace Company, 1997. 357 p. 
Dissociação entre forma e estrutura harmônica em obras de Claude Debussy e Igor... Adriano Claro Monteiro

\section{Publisher}

Universidade Federal de Goiás. Escola de Música e Artes Cênicas. Programa de Pós-graduação em Música. Publicação no Portal de Periódicos UFG.

As ideias expressadas neste artigo são de responsabilidade de seus autores, não representando, necessariamente, a opinião dos editores ou da universidade. 